\title{
Bone mineral density in patients with chronic heart failure: a meta-analysis
}

This article was published in the following Dove Press journal:

Clinical Interventions in Aging

\author{
Wenmin Xing ${ }^{1, *}$ \\ Xiaoling Lv',* \\ Wenyan $\mathrm{Gao}^{2}$ \\ Jirong Wang' \\ Zhouxin Yang' \\ Sanying Wang' \\ Jing Zhang' \\ Jing Yan'
}

'Zhejiang Provincial Key Laboratory of Geriatrics, Department of Geriatrics,

Zhejiang Hospital, ${ }^{2}$ Institute of

Materia Medica, Zhejiang Academy of

Medical Sciences, Hangzhou, China

*These authors contributed equally to this work
Correspondence: Jing Yan

Zhejiang Provincial Key Lab of Geriatrics,

Department of Geriatrics, Zhejiang

Hospital, 12 Lingyin Road, Hangzhou

310013 , China

Tel+8657l 8I595005

Email zjicu@vip.163.com
Objective: This study aimed to verify the existing relationship between bone mineral density (BMD) and chronic heart failure (CHF) by meta-analysis.

Methods: Databases, including PubMed, Web of Science, and Chinese National Knowledge Infrastructure, published in English or Chinese up to February 28, 2017, were searched for studies on the association between CHF and BMD. Two independent reviewers collected the relevant articles. The standard mean deviation (SMD) and 95\% confidence interval were calculated for BMD with fixed- and random-effect models. Subgroup and sensitivity analyses were also conducted.

Results: A total of six studies (552 CHF and 243 non-CHF patients) were included. The results indicated that the patients with CHF had a lower total BMD compared with the nonCHF patients. Similar effects were also observed for femoral neck, arm, leg, and trunk BMD. However, no difference was observed in the lumbar spine BMD. The SMD of total BMD in New York Heart Association classes I or II (NYHA I or II) patients was -0.62, while that in NYHA III or IV patients was -0.87 , and the SMD of femoral bone mineral density in NYHA I or II patients was -0.47 , while that in NYHA III or IV patients was -1.07 . Moreover, vitamin D and parathyroid hormone (PTH) were also found to be associated with CHF.

Conclusion: Patients with CHF had a lower total BMD and femoral neck, arm, leg, or trochanter BMD than patients with non-CHF. Vitamin D reduced, whereas PTH increased, with the severity of CHF. The clinical significance of the present findings remains uncertain and should be confirmed by future studies.

Keywords: bone mineral density, chronic heart failure, meta-analysis

\section{Introduction}

Aging is a complicated process that ultimately leads to morbidity, which has been considered as the major risk factor for various diseases including cardiovascular malfunctions, neurological disorders, ${ }^{1}$ metabolic disruptions, and cancer. ${ }^{2}$ As individuals age, many changes in body composition occur; for example, the body muscles, bone loss, and body fat increase and lean mass and bone mineral density (BMD) decrease. . $^{3,4}$ Moreover, changes in the body composition are due to alterations in energy balance, with a positive energy balance leading to weight gain and a negative balance resulting in weight loss. ${ }^{4,5}$ The resting metabolic rate reduces in the aging process, which may also lead to changes in body composition and vice versa. ${ }^{4}$ On the contrary, the cardioprotective systems decline during the aging process, contributing to the development of heart failure. ${ }^{6,7}$

As a result of increased aging population, the number of people older than 65 years in the US will reach $\sim 70$ million by 2030 , which is $\sim 20 \%$ of the total population. ${ }^{8}$ Approximately $50 \%$ of all heart failure diagnoses and $90 \%$ of all heart failure deaths 
occur in the population older than 70 years. In cardiovascular disorders, the morbidity of chronic heart failure (CHF) is increasing. Approximately 5.7 million Americans are affected with $\mathrm{CHF}^{6}$ The prevalence of $\mathrm{CHF}$ is $\sim 2 \%$ of the general population in the developed countries, increasing to $\sim 10 \%$ among people $>70$ years of age; moreover, the prevalence increased with age in both men and women..$^{9,10}$ $\mathrm{CHF}$ is a chronic multisystem disorder associated with a myriad of metabolic disturbances. It is the leading cause of hospitalization for acute care and of death in patients. ${ }^{11,12}$ Recently, the number of patients with CHF is increasing rapidly because of the aging of the population in the world. The quality of life of patients with CHF is very poor because of many debilitating symptoms, such as shortness of breath, sleep disorder, and frailty. ${ }^{13,14}$ Moreover, CHF may adversely affect bone metabolism and induce a severe bone loss, ${ }^{15}$ increasing susceptibility to fractures and osteoporosis.

Osteoporosis is the most common bone disease in humans, especially Caucasians, women, and older people, which is characterized by low BMD, deterioration of bone tissue, and disruption of bone microarchitecture, ${ }^{6,16}$ leading to an increase in the risk of fractures. Recently, osteoporosis is increasingly becoming a global epidemic with the increasing aging population. According to statistics, $>200$ million people are suffering from osteoporosis. ${ }^{3}$ A previous study has found that the lifetime risk of any fracture of the hip, spine, or distal forearm is $\sim 40 \%$ in white women and $13 \%$ in men. ${ }^{3}$

Both heart disease and osteoporosis are common causes of loss of function and independence and have become a heavy burden on the health care system. A previous study ${ }^{17}$ found that 177,639 patients were diagnosed as having fragility fractures between 2006 and 2010 in Apulia, of which $66.3 \%$ had cardiopathy with a higher prevalence in males and in patients $>80$ years of age. The incidence of femoral fracture $(51.9 \%)$ was the highest. In these patients, the incidence of cerebrovascular diseases was the highest, followed by arrhythmias, heart failure, and cardiomyopathies. ${ }^{17}$ Moreover, the relationship between BMD and heart failure risk may be different among different races. In nonblack men, the lower total hip BMD was associated with a higher risk of heart failure, with a hazard ratio of 1.13 (95\% confidence interval $[\mathrm{CI}]=1.01,1.26)$, whereas in black men, lower total hip BMD was associated with a lower risk of heart failure. No black men had total hip osteoporosis. However, among nonblack men, total hip osteoporosis was associated with a higher risk of heart failure compared with normal BMD US communities. ${ }^{18}$ In fact, the relationship between low BMD and CHF had also gained increased interest with raising awareness for preventing disease complications. The evidence of the association between CHF and osteopenia/ osteoporosis may help develop strategies for the prevention and treatment of patients with low BMD affected by CHF. A low BMD has been found in patients with advanced $\mathrm{CHF}$, especially in patients who are cachectic or candidates for cardiac transplantation. ${ }^{17,19}$ Patients with $\mathrm{CHF}$ evaluated for transplantation had a $40 \%$ low BMD. ${ }^{4,17}$ A significant bone loss over time (a reduction in bone mineral content, total $>1 \%$ per year) occurred in $35 \%$ of CHF men. ${ }^{11}$ Similar results were found in several previous studies. ${ }^{11,20-24}$ However, scarce and conflicting data have also been published on the relationship between $\mathrm{CHF}$ and bone mass loss of lumbar. ${ }^{24}$

Despite the importance of this subject, no scientific evidence and no clear consensus existed about this association. The aim of this meta-analysis was to verify the scientific evidence for the association between CHF and low BMD in elderly people.

\section{Methods}

\section{Search strategy}

Two investigators (Xiaoling LV and Wenyan Gao) independently conducted an electronic database search using PubMed, Web of Science, and Chinese National Knowledge Infrastructure (CNKI) from January 1, 2000, until February 20, 2017. The publication languages selected were English and Chinese. In PubMed, controlled vocabulary terms (Medical Subject Heading [MeSH]) and the following key words were used: (osteoporosis [MeSH terms] OR osteoporosis [text word] OR osteopenia [text word] OR "bone density" [MeSH terms] OR "bone mineral density" [text word] OR bone mass [text word] OR bone mass [MeSH terms]) AND ("chronic heart failure" [MeSH terms] OR "chronic heart failure" [text word] OR "congestive heart failure" [MeSH terms] OR "congestive heart failure" [text word]). In Web of Science, the following keywords were used: "('osteoporosis' OR 'osteopenia' OR ‘bone mineral density' OR 'bone density 'OR 'bone mass') AND ('chronic heart failure' OR 'congestive heart failure')." In CNKI, the following search terms were used: osteoporosis, osteopenia, bone mineral density, bone density, bone mass, chronic heart failure, and congestive heart failure.

Additionally, all subjects were published in the primary studies to avoid duplicating analyses. All clearly irrelevant studies, such as case reports, and review articles were excluded. The relevant studies cited in the reference of review articles were also searched manually for additional eligible studies. 


\section{Study selection}

Two researchers (Jirong Wang and Zhouxin Yang) independently evaluated the titles and abstracts of the identified articles to decide whether they met the study criteria. Differences, if any, were solved by consensus. Both cross-sectional and longitudinal studies comparing data on osteoporosis and BMD were included. Studies were included only when they 1) reported on mean values of $\mathrm{BMD}$, along with SD or standard error (SE), in at least one site and 2) included patients with CHF and healthy individual control. Additionally, the most relevant publications were included if the study was published more than once. Studies were excluded if they were 1) without a control group or the control group did not include a cognitively normal person and 2) abstracts, case reports, letters, reviews, meta-analyses, animal experiments, or unpublished studies.

However, when 1) the BMD data could not be metaanalyzed (eg, no mean and SD or no data on BMD provided for the control group) and 2) other relevant information (eg, age and percentage of females) was missing, the authors were contacted asking for further information.

\section{Data extraction}

Data extraction was performed independently by two researchers (Sanying Wang and Jing Zhang). Any disagreement between the two examiners was solved by a third researcher (Xiaoling LV). The following information were extracted: 1) study characteristics (eg, name of the first author, year of publication, design of the study, and country where the study was performed), 2) study population characteristics (eg, patient characteristics, sample size, and demographics), 3) mean BMD and SDs or SEs of both patients and control individuals, 4) matching variables between patients with CHF and controls, and 5) method of ascertainment for BMD assessment.

\section{Statistical analysis}

Continuous variables (BMD) were analyzed using a standard mean deviation (SMD) and 95\% CI. The heterogeneity of results across trials was assessed using the $I^{2}$ statistic, which describes the percentage of total variation across studies that was attributable to heterogeneity rather than to chance. The $I^{2}$ values of $25 \%, 50 \%$, and $75 \%$ corresponded to cutoff points for low, moderate, and high degrees of heterogeneity, respectively. The $I^{2}$ value $>50 \%$ indicated a lack of heterogeneity among the studies. Thus, the pooled effect was calculated using the fixed-effects model. Otherwise, a random-effects model was used in the case of significant heterogeneity across studies. A sensitivity analysis was performed to evaluate the influence of each individual study on overall estimates. The Begg's and Egger's tests were used to assess potential publication bias. All statistical analyses were conducted by Stata software version 12.0 (StataCorp LP, College Station, TX, USA). A $P$-value $<0.05$ was considered statistically significant.

\section{Results \\ Included studies}

A total of 1,531 articles were identified and retrieved. The main databases used as sources for studies were PubMed $(n=530)$, Web of Science $(n=981)$, and CNKI $(n=20)$. The 671 duplicated articles were removed. All titles and abstracts ( $n=14$ ) were analyzed according to the study criteria, and eight were excluded. Therefore, six studies were eligible in the BMD analysis. ${ }^{11,20-25}$ The flowchart of the study selection process is shown in Figure 1. In total, 805 individuals (552 patients with CHF and 243 controls) were included.

\section{Characteristics of studies and subjects}

The characteristics of selected studies are summarized in Table 1. A total of six studies were conducted in Egypt, Serbia, Poland, China, and Greece. Four studies were longitudinal population-level cohort studies, ${ }^{20,25}$ and two were case-control studies. ${ }^{11,22-24}$ The studies included were published during the years 2000-2016. Sample sizes varied between studies (73-214), as presented in Table 2. ${ }^{23,24}$ The patient group included totally 552 people with CHF and an age-matched control population of 243 people without any current or history of CHF. Three studies evaluated

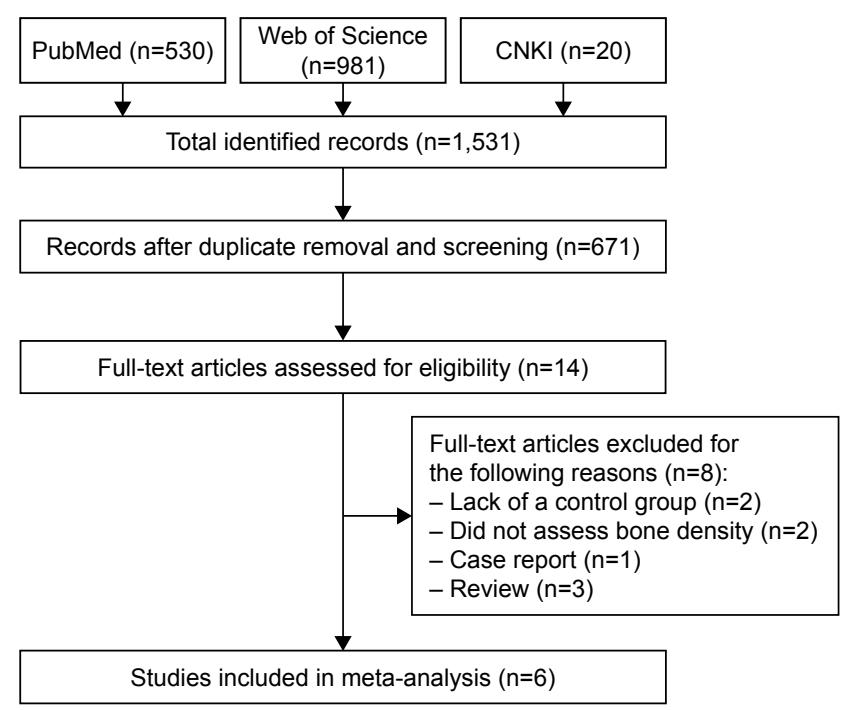

Figure I Flow diagram of the published data search. Abbreviation: CNKI, Chinese National Knowledge Infrastructure. 
Table I Characteristics of the eligible studies

\begin{tabular}{|c|c|c|c|c|c|c|c|c|}
\hline References & Year & Country & Design & $\begin{array}{l}\text { Patients (CHF/ } \\
\text { controls), n }\end{array}$ & Study period & Inclusion criteria & $\begin{array}{l}\text { BMD } \\
\text { instrument }\end{array}$ & $\begin{array}{l}\text { Bone } \\
\text { measurement }\end{array}$ \\
\hline 25 & 2009 & Egypt & $\begin{array}{l}\text { Case-control } \\
\text { study }\end{array}$ & I $37(83 / 54)$ & Not reported & An EF $<40 \%$. & DEXA scan & $\begin{array}{l}\text { Femoral BMD } \\
\text { and lumbar spine } \\
\text { BMD }\end{array}$ \\
\hline 20 & 2010 & Serbia & $\begin{array}{l}\text { Case-control } \\
\text { study }\end{array}$ & $93(73 / 20)$ & Not reported & $\begin{array}{l}\text { Duration of CHF for longer } \\
\text { than I year; left ventricular } \\
\text { ejection fraction } 40 \% \text {; } \\
\text { unchanged medication } \\
\text { regimen within the previous } \\
6 \text { weeks; clinically stable } \\
\text { condition with no clinical } \\
\text { evidence of decompensate } \\
\text { heart failure. }\end{array}$ & DEXA scan & $\begin{array}{l}\text { Total BMD and } \\
\text { lumbar spine } \\
\text { BMD }\end{array}$ \\
\hline 11 & 2009 & Poland & Cohort study & $208(|87 / 2|)$ & $\begin{array}{l}\text { October } 2000 \text { to } \\
\text { September } 2004\end{array}$ & $\begin{array}{l}\text { A } \geq 6 \text { month history of } \\
\text { CHF; an LV EF }<45 \% \text {; } \\
\text { clinical stability and } \\
\text { unchanged medications for } \\
\text { at least I month. }\end{array}$ & DEXA scan & $\begin{array}{l}\text { Total BMD, leg } \\
\text { BMD, arms BMD, } \\
\text { and trunk BMD }\end{array}$ \\
\hline 22 & 2014 & China & Cohort study & $80(40 / 40)$ & $\begin{array}{l}\text { January } 2012 \text { to } \\
\text { December } 2012\end{array}$ & Inclusion by $\mathrm{CHF}$ criteria. & DEXA scan & $\begin{array}{l}\text { Femoral BMD } \\
\text { and lumbar spine } \\
\text { BMD }\end{array}$ \\
\hline 23 & 2012 & Greece & Cohort study & $73(60 / 13)$ & $\begin{array}{l}\text { August } 2007 \text { to } \\
\text { August } 2009\end{array}$ & $\begin{array}{l}A \geq 6 \text { month history of } \\
C H F ; \text { an } L V E F, 40 \% \text {; a stable } \\
\text { clinical status and medication } \\
\text { regimen for } \geq I \text { month } \\
\text { preceding enrollment. }\end{array}$ & DEXA scan & $\begin{array}{l}\text { Femoral BMD } \\
\text { and total body } \\
\text { BMD }\end{array}$ \\
\hline 24 & 2016 & China & Cohort study & $214(109 / 95)$ & $\begin{array}{l}\text { August } 2014 \text { to } \\
\text { May } 2015\end{array}$ & $\mathrm{~A} \geq 6$ month history of CHF. & DEXA scan & $\begin{array}{l}\text { Trunk BMD and } \\
\text { Femoral BMD }\end{array}$ \\
\hline
\end{tabular}

Abbreviations: BMD, bone mineral density; CHF, chronic heart failure; DEXA, dual-energy X-ray absorptiometry; LV, left ventricular; EF, ejection fraction.

only male participants, ${ }^{11,20,23}$ and the rest included both male and female participants. ${ }^{22,24,25}$ The controls in each study were selected based on a matching process (based on one variable or more such as age, body mass index, physical activity, and medical condition/medications). All studies assessed BMD through dual-energy X-ray absorptiometry. Four studies measured BMD at the femoral neck bone, ${ }^{22-25}$ three measured BMD at the lumbar spine, ${ }^{20,22,25}$ three measured BMD of the total body bone density, ${ }^{11,20,23}$ three measured BMD at the trunk, ${ }^{11,23,24}$ and two measured BMD at the arms and legs. ${ }^{11,23}$
Details of the included studies and participants are presented in Tables 1 and 2.

\section{Association between CHF and BMD Total body BMD}

The pooled BMD estimates from three studies revealed that patients with $\mathrm{CHF}$ had a reduced $\mathrm{BMD}$ of total body $(\mathrm{SMD}=-0.77,95 \% \mathrm{CI}=-0.96,-0.58, P=0.000$; Figure $2 \mathrm{~A}$ ). Neither the Begg's nor the Egger's tests showed evidence of significant publication bias. In the subgroup analysis by

Table 2 Characteristics of the participants in the included references

\begin{tabular}{|c|c|c|c|c|c|c|c|c|c|}
\hline \multirow[t]{2}{*}{ References } & \multirow{2}{*}{$\begin{array}{l}\text { Participants } \\
\text { (patients/ } \\
\text { controls), n }\end{array}$} & \multicolumn{2}{|c|}{ Age, years, mean \pm SD } & \multirow{2}{*}{$\begin{array}{l}\text { Male } \\
\text { (female) }\end{array}$} & \multicolumn{2}{|c|}{ BMI, kg/m², mean \pm SD } & \multicolumn{2}{|c|}{ LV EF, $\%$, mean \pm SD } & \multirow{2}{*}{$\begin{array}{l}\text { NYHA } \\
\text { class }\end{array}$} \\
\hline & & Patients & Controls & & Patients & Controls & Patients & Controls & \\
\hline 25 & I $37(83 / 54)$ & $69.9 \pm 4.5$ & $70.1 \pm 3.9$ & $137(67)$ & $27.9 \pm 4.1$ & $27.5 \pm 3.8$ & $33 \pm 5.5$ & $59 \pm 6.2$ & I-IV \\
\hline 20 & $93(73 / 20)$ & $68 \pm 7$ & $67 \pm 7$ & $93(0)$ & $28 \pm 5$ & $28 \pm 3$ & $29 \pm 8$ & $65 \pm 5$ & II-III \\
\hline II & $208(|87 / 2|)$ & $60 \pm 1$ & $57 \pm 7$ & $208(0)$ & $27.1 \pm 4.6$ & $28.9 \pm 4.5$ & $32 \pm 7$ & $59 \pm 4$ & I-IV \\
\hline 22 & $80(40 / 40)$ & 74 (mean) & 75 (mean) & $80(18)$ & $19.76 \pm 2.26$ & $21.98 \pm 2.34$ & NR & NR & I-IV \\
\hline 23 & $73(60 / 13)$ & $57 \pm 11$ & $57 \pm 10$ & $73(0)$ & $27.7 \pm 4.3$ & $28.1 \pm 3.3$ & $26 \pm 6$ & $59 \pm 4$ & I-IV \\
\hline 24 & $214(109 / 95)$ & $63.78 \pm 7.17$ & $62.56 \pm 6.23$ & $214(58)$ & NR & NR & $47.31 \pm 12.53$ & $61.27 \pm 4.35$ & II-IV \\
\hline
\end{tabular}

Abbreviations: BMI, body mass index; LV, left ventricular; EF, ejection fraction; NR, not reported; NYHA, New York Heart Association. 
severity of CHF, the BMD of the New York Heart Association classes I or II (NYHA I or II) group ( $\mathrm{SMD}=-0.62$; $95 \% \mathrm{CI}=-0.95,-0.28 ; P=0.000)$ in two studies was significantly reduced compared with the control groups. The

BMD of the NYHA III or IV group (SMD=-0.87; 95\%
$\mathrm{CI}=-1.16,-0.58 ; P=0.000)$ in three studies was significantly reduced compared with the control groups, which was more serious than that in the NYHA I or II group (Figure 2B). Therefore, the result of the SMD values exhibited that the reduction in the total body bone loss in

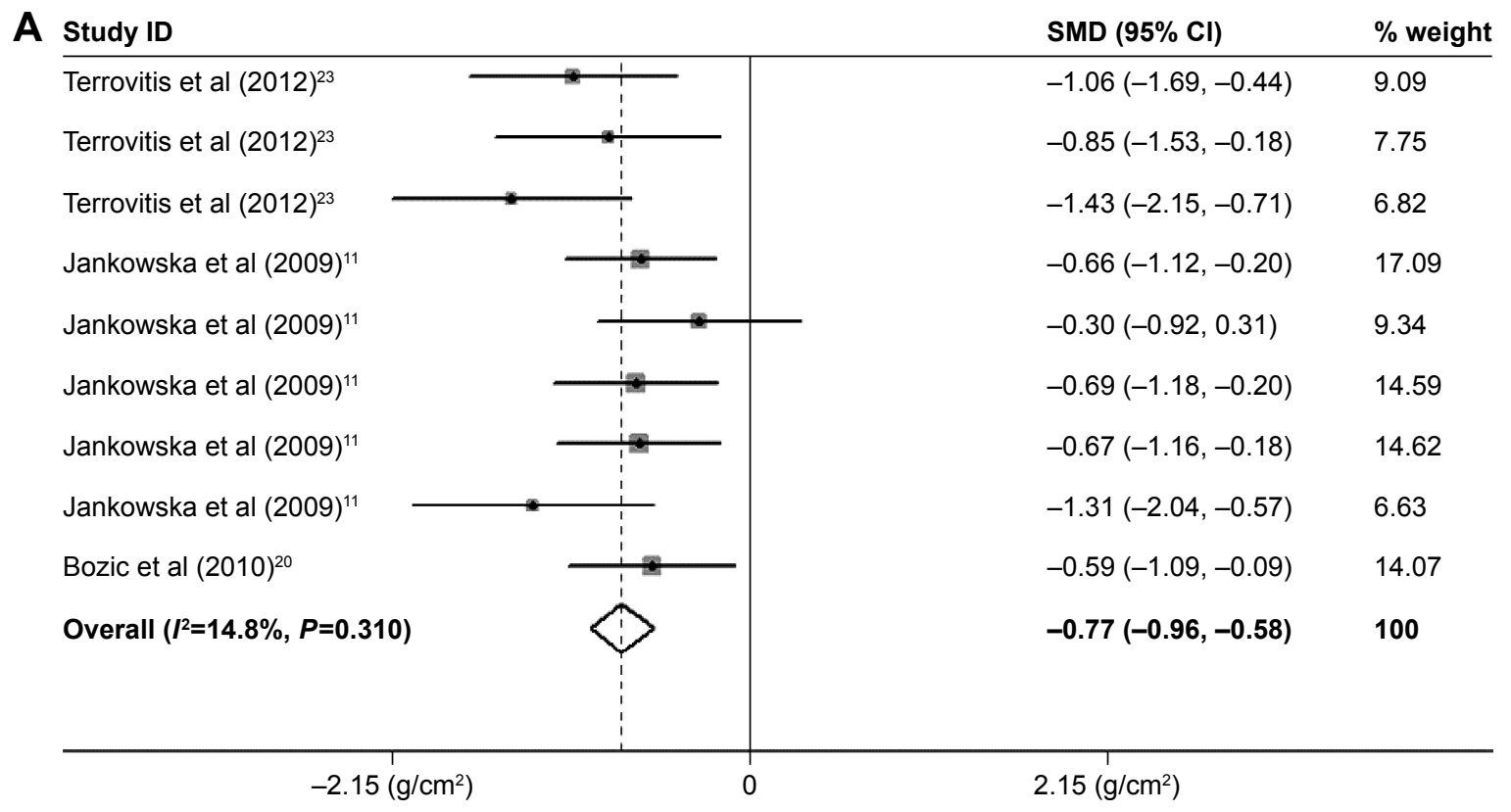

B Study ID

\section{NYHA I or II}

Terrovitis et al (2012) $)^{23}$

Jankowska et al (2009) ${ }^{11}$ (NYHA I)

Jankowska et al (2009)11 (NYHA II)

Subtotal $\left(I^{2}=0.0 \%, P=0.461\right)$

NYHA III or IV

Jankowska et al (2009) ${ }^{11}$ (NYHA III)

Jankowska et al (2009) ${ }^{11}$ (NYHA IV)

Bozic et al (2010) ${ }^{20}$

Terrovitis et al $(2012)^{23}$

Subtotal $\left(I^{2}=45.8 \%, P=0.437\right)$

Overall $\left(I^{2}=27.8 \%, P=0.216\right)$

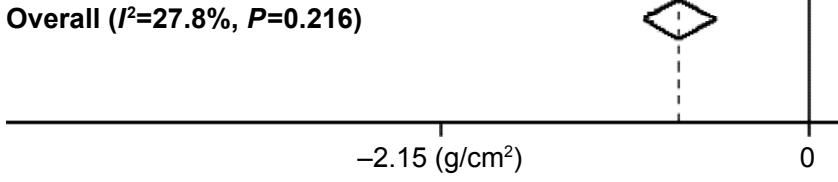

SMD $(95 \% \mathrm{Cl})$

$-0.85(-1.53,-0.18)$

10.49

$-0.30(-0.92,0.31)$

12.66

$-0.69(-1.18,-0.20)$

19.76

$-0.62(-0.95,-0.28)$

42.91
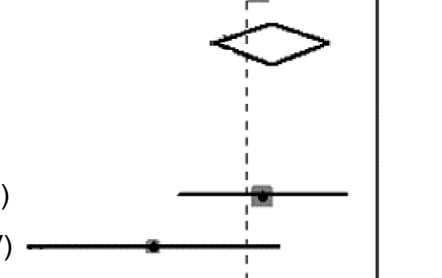

$-0.67(-1.16,-0.18) \quad 19.81$

$-1.31(-2.04,-0.57) \quad 8.97$

$-0.59(-1.09,-0.09) \quad 19.06$

$-1.43(-2.15,-0.71) \quad 9.24$

$-0.87(-1.16,-0.58) \quad 57.09$

$-0.76(-0.98,-0.54) \quad 100$

Figure 2 Meta-analysis of the differences in BMD of the total body in CHF.

Notes: (A) Total body BMD. Terrovitis et a ${ }^{23}$ data shown in order of total group, NYHA I or NYHA II group, and NYHA III or IV group, respectively. Jankowska at al data shown in order of total group, NYHA I, NYHA II, NYHA III, and NYHA IV group, respectively. (B) Subgroup analysis of total body BMD by severity of CHF. For each study, the estimate of mean BMD difference and its $95 \% \mathrm{Cl}$ are plotted with a diamond and a horizontal line, respectively.

Abbreviations: $\mathrm{BMD}$, bone mineral density; $\mathrm{CHF}$, chronic heart failure; $\mathrm{Cl}$, confidence interval; SMD, standard mean deviation. 
patients with NYHA III or IV was more serious than that in patients with NYHA I or II.

\section{Femoral neck BMD}

The association between CHF and BMD at the femoral neck site was statistically analyzed in four studies, which was significantly different $(\mathrm{SMD}=-0.73 ; 95 \% \mathrm{CI}=-0.96,-0.50$; $P=0.000$; Figure 3A). In the subgroup analysis by severity of $\mathrm{CHF}$, the BMD of the NYHA I or II group (SMD $=-0.47 ; 95 \%$ $\mathrm{CI}=-0.78,-0.15 ; P=0.004)$ in two studies was significantly reduced compared with the control groups. The BMD of the NYHA III or IV group (SMD $=-1.07 ; 95 \% \mathrm{CI}=-1.37,-0.76$; $P=0.000)$ in three studies was significantly reduced compared with the control groups, which was more serious than that in the NYHA I or II group (Figure 3B). Neither the Begg's nor the Egger's tests demonstrated evidence of significant publication bias. Therefore, the reduction of BMD in femoral neck in patients with NYHA III or IV was more serious compared with the patients with NYHA I or II.

\section{Lumbar spine BMD}

The association between CHF and BMD at the lumbar spine site was also statistically analyzed in four studies and was found to be significantly different $(\mathrm{SMD}=-5.26 ; 95 \%$ $\mathrm{CI}=-7.91,-2.61 ; P=0.000$; Figure $3 \mathrm{C}$ ). Evidence of heterogeneity $\left(I^{2}=98.9 \%\right)$ was found. Neither the Begg's nor the Egger's tests showed evidence of significant publication bias. Finally, the sensitivity analysis was used to investigate the source of heterogeneity among the eligible studies. At the same time, the SMD of Abou-Raya and Abou-Raya ${ }^{25}$ was out of range of upper CI limit (Figure S1). The SMD of AbouRaya and Abou-Raya ${ }^{25}$ was very large, which was -80.083 . The pooled result was found to vary dramatically after removing the study by Abou-Raya and Abou-Raya ${ }^{25}$ (SMD=-0.296; 95\% CI=-0.88, $-0.29 ; P=0.321$; heterogeneity $I^{2}: 84.2 \%$; Figure 3D).

\section{Trunk, arm, and leg BMD}

Data from six estimates across three unique studies demonstrated that patients with $\mathrm{CHF}$ had a significantly reduced leg BMD (SMD=-0.43; 95\% CI $=-0.63,-0.23 ; P=0.000$; Figure 4A), arm BMD (SMD $=-0.74 ; 95 \% \mathrm{CI}=-0.94,-0.54$; $P=0.000$; Figure 4C), and trunk BMD (SMD $=-0.87 ; 95 \%$ $\mathrm{CI}=-1.12,-0.63 ; P=0.000$; Figure $5 \mathrm{~A}$ ) compared with the controls. The Begg's and Egger's tests demonstrated no significant publication bias. In the subgroup analysis by

\begin{tabular}{|c|c|c|c|}
\hline $\begin{array}{l}\text { A } \\
\text { Study ID }\end{array}$ & & SMD $(95 \% \mathrm{Cl})$ & $\begin{array}{l}\% \\
\text { weight }\end{array}$ \\
\hline Terrovitis et al $(2012)^{23}$ & $\rightarrow-$ & $-0.99(-1.61,-0.37)$ & 8.01 \\
\hline Terrovitis et al (2012) $)^{23}$ & $\rightarrow$ & $-0.63(-1.30,0.03)$ & 7.36 \\
\hline Terrovitis et al $(2012)^{23}$ & $\longrightarrow$ & $-1.42(-2.14,-0.70)$ & 6.64 \\
\hline Abou-Raya and Abou-Raya $(2009)^{25}$ & $\rightarrow$ & $-0.28(-0.63,0.06)$ & 13.82 \\
\hline Zhu et al $(2016)^{24}$ & + & $-0.78(-1.06,-0.49)$ & 15.36 \\
\hline Zhu et al $(2016)^{24}$ & $\rightarrow$ & $-0.42(-0.78,-0.05)$ & 13.32 \\
\hline Zhu et al $(2016)^{24}$ & $\rightarrow$ & $-0.84(-1.24,-0.43)$ & 12.30 \\
\hline Zhu et al $(2016)^{24}$ & $\rightarrow$ & $-1.17(-1.60,-0.75)$ & 11.80 \\
\hline Qian and $\mathrm{Xu}(2014)^{22}$ & $\rightarrow$ & $-0.48(-0.92,-0.03)$ & 11.38 \\
\hline Overall $\left(I^{2}=58.1 \%, P=0.014\right)$ & 0 & $-0.73(-0.96,-0.50)$ & 100 \\
\hline-4 & 0 & 1 & \\
\hline
\end{tabular}

\section{C}

\begin{tabular}{|c|c|c|c|}
\hline Study ID & & SMD $(95 \% \mathrm{Cl})$ & $\begin{array}{l}\% \\
\text { weight }\end{array}$ \\
\hline Abou-Raya and Abou-Raya (2009) ${ }^{25}\langle$ & & $-80.08(-89.64,-70.52)$ & 6.19 \\
\hline Bozic et al $(2010)^{20}$ & $\#$ & $-0.65(-1.15,-0.14)$ & 31.16 \\
\hline Qian and Xu $(2014)^{22}$ & $=$ & $-0.53(-0.97,-0.08)$ & 31.24 \\
\hline Zhu et al $(2016)^{24}$ & F & $0.20(-0.07,0.48)$ & 31.41 \\
\hline $\begin{array}{l}\text { Overall }\left(I^{2}=98.9 \%,\right. \\
P=0.000)\end{array}$ & & $-5.26(-7.91,-2.61)$ & 100 \\
\hline-12 & 0 & 12 & \\
\hline
\end{tabular}

B

\begin{tabular}{|c|c|c|}
\hline Study ID & SMD $(95 \% \mathrm{Cl})$ & $\begin{array}{l}\% \\
\text { weight }\end{array}$ \\
\hline \multicolumn{3}{|l|}{ NYHA I or II } \\
\hline Terrovitis et al $(2012)^{23}$ & $-0.63(-1.30,0.03)$ & 15.24 \\
\hline Zhu et al $(2016)^{24}$ & $-0.42(-0.78,-0.05)$ & 24.87 \\
\hline Subtotal $\left(I^{2}=0.0 \%, P=0.575\right)$ & $-0.47(-0.78,-0.15)$ & 40.11 \\
\hline \multicolumn{3}{|l|}{ NYHA III or IV } \\
\hline Zhu et al $(2016)^{24}$ & $-0.84(-1.24,-0.43)$ & 23.36 \\
\hline Zhu et al $(2016)^{24}$ & $-1.17(-1.60,-0.75)$ & 22.59 \\
\hline Terrovitis et al $(2012)^{23}$ & $-1.42(-2.14,-0.70)$ & 13.93 \\
\hline Subtotal $\left(I^{2}=16.0 \%, P=0.304\right)$ & $-1.07(-1.37,-0.76)$ & 59.89 \\
\hline Overall $\left(I^{2}=61.3 \%, P=0.035\right)$ & $-0.86(-1.21,-0.51)$ & 100 \\
\hline-4 & 4 & \\
\hline
\end{tabular}

D

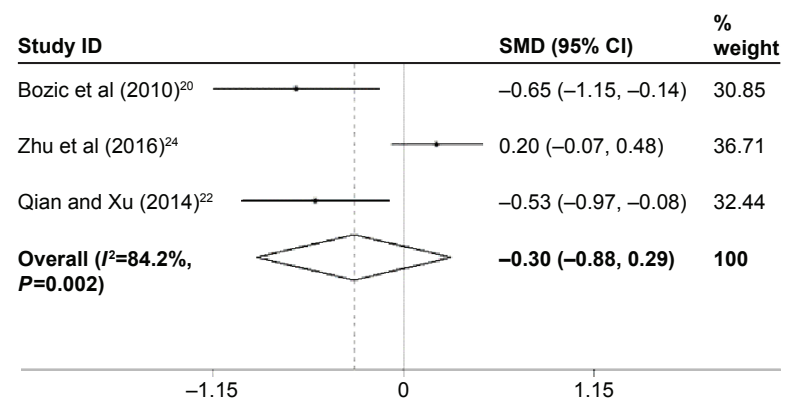

Figure 3 Forest plots for (A) femoral neck BMD, (B) subgroup analysis of femoral neck BMD by severity of CHF, (C) lumbar spine BMD, and (D) lumbar spine BMD after removing the Abou-Raya and Abou-Raya study.

Notes: For each study, the estimate of mean BMD difference and its $95 \% \mathrm{Cl}$ are plotted with a diamond and a horizontal line, respectively. Weights are from random-effects analysis. Terrovitis et a ${ }^{23}$ data shown in order of total group, NYHA I or NYHA II group, and NYHA III or IV group, respectively. Zhu et al ${ }^{24}$ data shown in order of NYHA I, NYHA II. NYHA III, and NYHA IV group, respectively (A) and NYHA III and NYHA IV group, respectively (B).

Abbreviations: $\mathrm{BMD}$, bone mineral density; $\mathrm{CHF}$, chronic heart failure; $\mathrm{Cl}$, confidence interval; SMD, standard mean deviation. 


\section{A}

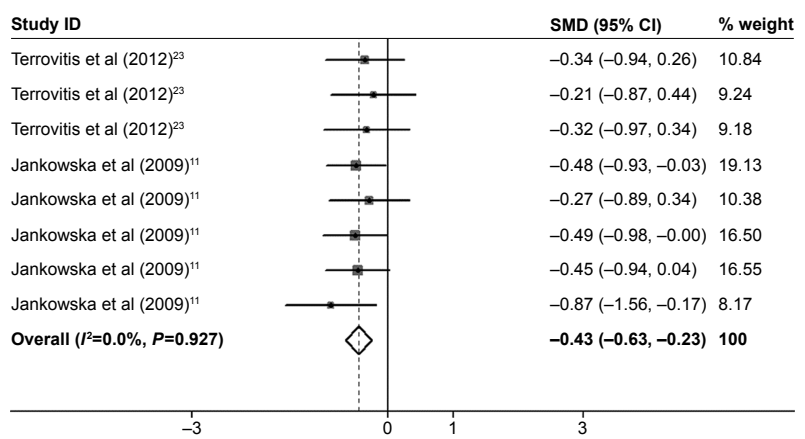

C

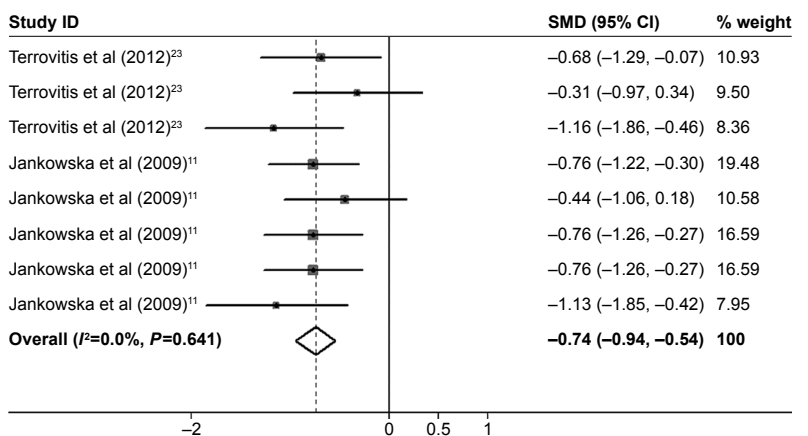

B

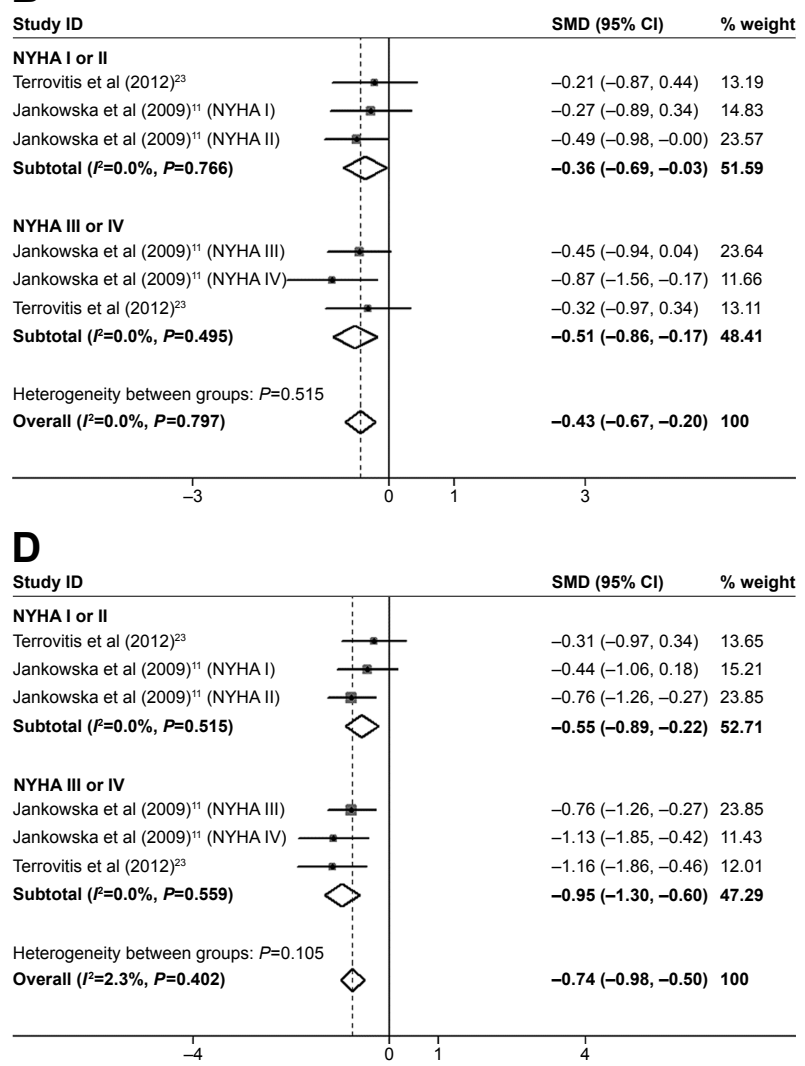

Figure 4 Forest plots for (A) legs BMD, (B) subgroup analysis of legs BMD by severity of CHF, (C) arms BMD, and (D) subgroup analysis of legs BMD by severity of CHF. Notes: For each study, the estimate of mean BMD difference and its $95 \% \mathrm{Cl}$ are plotted with a diamond and a horizontal line, respectively. (A and C) Terrovitis et al ${ }^{23}$ data shown in order of total group, NYHA I or NYHA II group, and NYHA III or IV group, respectively. Jankowska at al data shown in order of total group, NYHA I, NYHA II, NYHA III, and NYHA IV group, respectively.

Abbreviations: $\mathrm{BMD}$, bone mineral density; $\mathrm{CHF}$, chronic heart failure; $\mathrm{Cl}$, confidence interval; SMD, standard mean deviation.

sex, the association between CHF and trunk BMD was also statistically significant in the men's group ( $\mathrm{SMD}=-0.84$; $95 \% \mathrm{CI}=-1.11,-0.56 ; P=0.000)$ and the men and women's group $(\mathrm{SMD}=-0.91 ; 95 \% \mathrm{CI}=-1.36,-0.46 ; P=0.000$; Figure 5C). In the subgroup analysis by severity of $\mathrm{CHF}$, the trunk BMD (SMD $=-0.52 ; 95 \% \mathrm{CI}=-0.74,-0.29 ; P=0.000$; Figure 5B), arm BMD (SMD $=-0.55 ; 95 \% \mathrm{CI}=-0.89,-0.22$; $P=0.001$; Figure 4D), and leg $\mathrm{BMD}(\mathrm{SMD}=-0.36 ; 95 \%$ $\mathrm{CI}=-0.69,-0.03 ; P=0.034$; Figure $4 \mathrm{~B}$ ) of the NYHA I or II group were significantly reduced compared with the control groups. The reduction of the trunk bone loss in trunk BMD (SMD $=-1.20 ; 95 \% \mathrm{CI}=-1.60,-0.79 ; P=0.000$; Figure 5B), arm BMD (SMD $=-0.95 ; 95 \% \mathrm{CI}=-1.30,-0.60$; $P=0.000$; Figure 4D), and leg BMD (SMD $=-0.51 ; 95 \%$ $\mathrm{CI}=-0.86,-0.17 ; P=0.003$; Figure $4 \mathrm{~B}$ ) of the NYHA III or IV group was significant compared with the control group, which was more serious than that of the NYHA I or II group. Neither the Begg's nor the Egger's tests exhibited evidence of significant publication bias. Therefore, the reduction in trunk bone loss in patients with NYHA III or IV was more serious compared with the patients with NYHA I or II.

\section{Association between CHF and parathyroid hormone (PTH) and vitamin D}

Three studies in the present meta-analysis compared the PTH level between the patients with CHF and non-CHF patients. The pooled analysis revealed that PTH was markedly increased in patients with $\mathrm{CHF}$ ( $\mathrm{SMD}=1.24 ; 95 \% \mathrm{CI}=0.97$, $1.50 ; P=0.000$; Figure $6 \mathrm{~A}$ ). Four of six studies also reported the vitamin D concentration of the patients with CHF. The present study indicated that the level of vitamin $\mathrm{D}$ was markedly decreased $(\mathrm{SMD}=-1.73 ; 95 \% \mathrm{CI}=-3.27,-0.18$; $P=0.028$ ) in patients with CHF compared with the nonCHF patients (Figure 6B). The levels of PTH and vitamin D changed with the reduction in BMD in patients with $\mathrm{CHF}$.

\section{Discussion}

The present study was based on six studies and indicated that patients with CHF had a greater bone loss compared with the healthy individuals. The present meta-analysis was perhaps the first study on this topic. Data from the meta-analysis revealed a significantly reduced BMD at the femoral neck, hip, trunks, arms, and legs in patients with CHF. In the BMD 
A

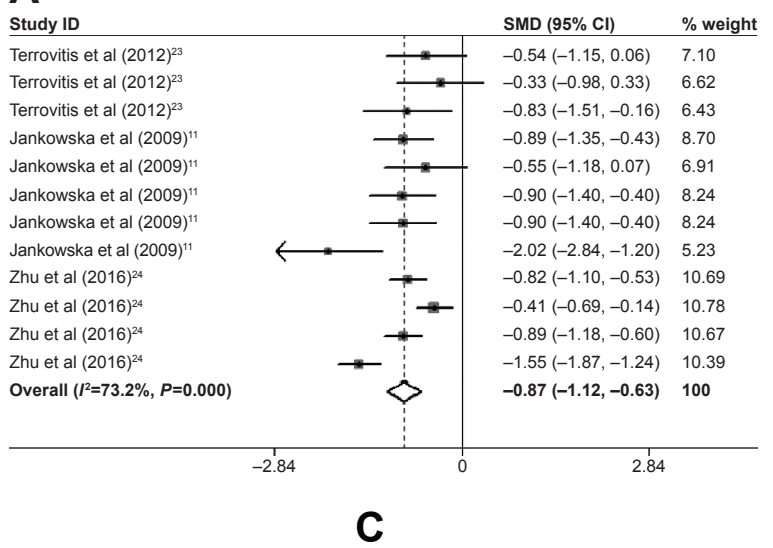

B

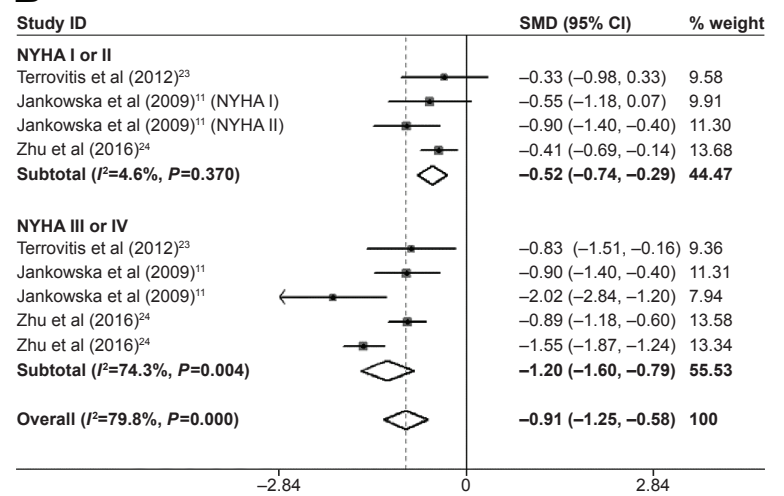

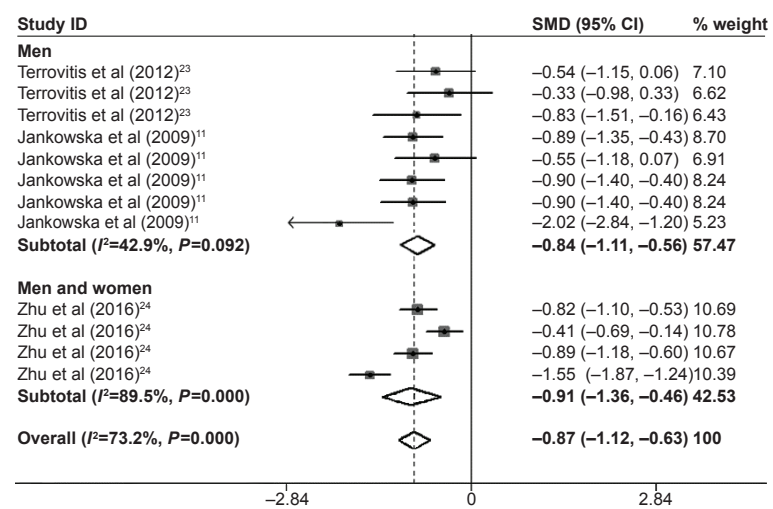

Figure 5 Forest plots for (A) trunk BMD, (B) subgroup analysis of trunk BMD by severity of CHF, and (C) subgroup analysis of trunk BMD by sex.

Notes: For each study, the estimate of mean BMD difference and its $95 \% \mathrm{Cl}$ are plotted with a diamond and a horizontal line, respectively. Weights are from random-effects analysis. (A and C) Terrovitis et a ${ }^{23}$ data shown in order of total group, NYHA I or NYHA II group, and NYHA III or IV group, respectively. Jankowska at al data shown in order of total group, NYHA I, NYHA II, NYHA III, and NYHA IV group, respectively (A), and NYHA III and NYHA IV, respectively (B). Zhu et al ${ }^{24}$ data shown in order of NYHA I, NYHA II. NYHA III, and NYHA IV group, respectively (A and C) and NYHA III and NYHA IV group, respectively (B).

Abbreviations: $\mathrm{BMD}$, bone mineral density; $\mathrm{CHF}$, chronic heart failure; $\mathrm{Cl}$, confidence interval; SMD, standard mean deviation.

analysis of the lumbar spine, this study (Abou-Raya and Abou-Raya ${ }^{25}$ ) provided a lumbar spine BMD data (control groups: $\left.1.977 \pm 0.010 \mathrm{~g} / \mathrm{cm}^{2}\right)$, which was obviously obtained from the normal BMD value. ${ }^{26}$ Therefore, this study was removed from the lumbar spine meta-analysis. No difference was found in the lumbar spine BMD between patients with CHF and non-CHF patients. The mean age of the patients in the present study was $57-70$ years. Osteoporosis is a disease of the older population, most commonly seen in postmenopausal women and men over 65 years. ${ }^{3}$ EWA et al found that the BMD of patients with CHF was not different compared with non-CHF patients. ${ }^{11}$ However, when the BMD of patients with CHF were analyzed, the bone loss was correlated with CHF severity (NYHA class), which may be because the CHF disease impaired the exercise capacity. Osteoporosis (T-score $=<-2.5)$ or osteopenia $(-2.5<\mathrm{T}$-score $<-1.0)$ was present more frequently in patients with CHF in the NYHA III and IV groups than in the NYHA I and II groups. ${ }^{3}$ Therefore, the BMD loss was closely correlated with the severity of CHF, which was concordant with the present meta-analysis result.
Some of the included studies in the present meta-analysis demonstrated lower vitamin D levels compared with the control group, suggesting that the reason of bone loss was vitamin D deficiency. Similar conclusions were given in some other studies, which are not included in this metaanalysis. ${ }^{3,6}$ This status was possible due to reduced outdoor activities leading to reduced vitamin D synthesis in the skin, which might negatively affect calcium balance because the low vitamin $\mathrm{D}$ status results in low calcium absorption rates and an increased bone turn over. Low levels of vitamin D metabolite concentrations have been reported in patients with CHF. ${ }^{3}$ Indeed, in the included studies, patients with CHF had lower calcitriol levels than the group of age-matched and sex-matched controls. Moreover, except for the low level of vitamin $\mathrm{D}$, the other experimental evidence showed that secondary hyperparathyroidism (PTH) had an association with CHF as well as with reduced BMD in CHF or bone fracture risk and CHF. ${ }^{3}$ Actually, other reports had also demonstrated that the loss of bone mass in patients with CHF was accompanied by reduced fat and lean tissue mass. ${ }^{11}$ 
A Study ID

$\operatorname{SMD}(95 \% \mathrm{Cl})$

$\%$ weight

Terrovitis et al $(2012)^{23}$

Terrovitis et al $(2012)^{23}$

Terrovitis et al (2012) ${ }^{23}$

Bozic et al $(2010)^{20}$

Qian and Xu (2014) $)^{22}$

Overall $\left(I^{2}=32.8 \%, P=0.203\right)$

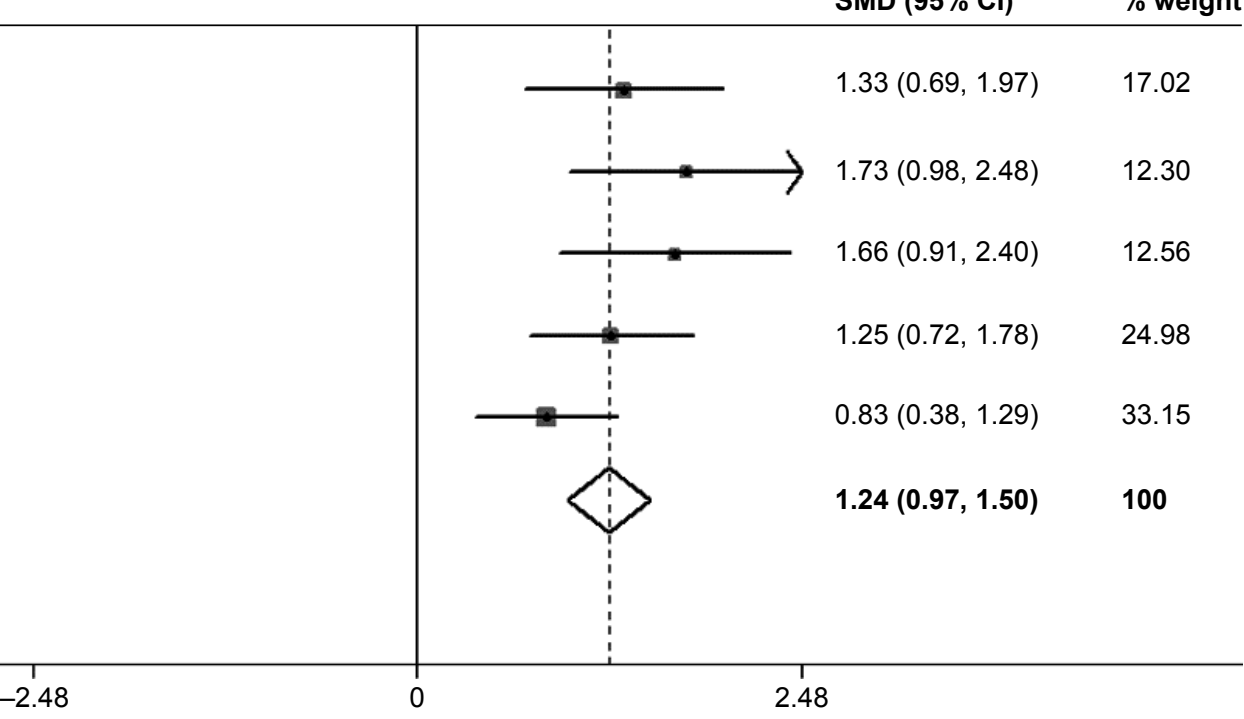

B Study ID

MD $(95 \% \mathrm{Cl})$

$\%$ weight

Terrovitis et al $(2012)^{23}$

Terrovitis et al (2012) ${ }^{23}$

Terrovitis et al $(2012)^{23}$

Bozic et al $(2010)^{20}$

Abou-Raya and Abou-Raya (2009) ${ }^{25}$

Qian and Xu (2014) $)^{22}$

Overall $\left(I^{2}=97.4 \%, P=0.000\right)$

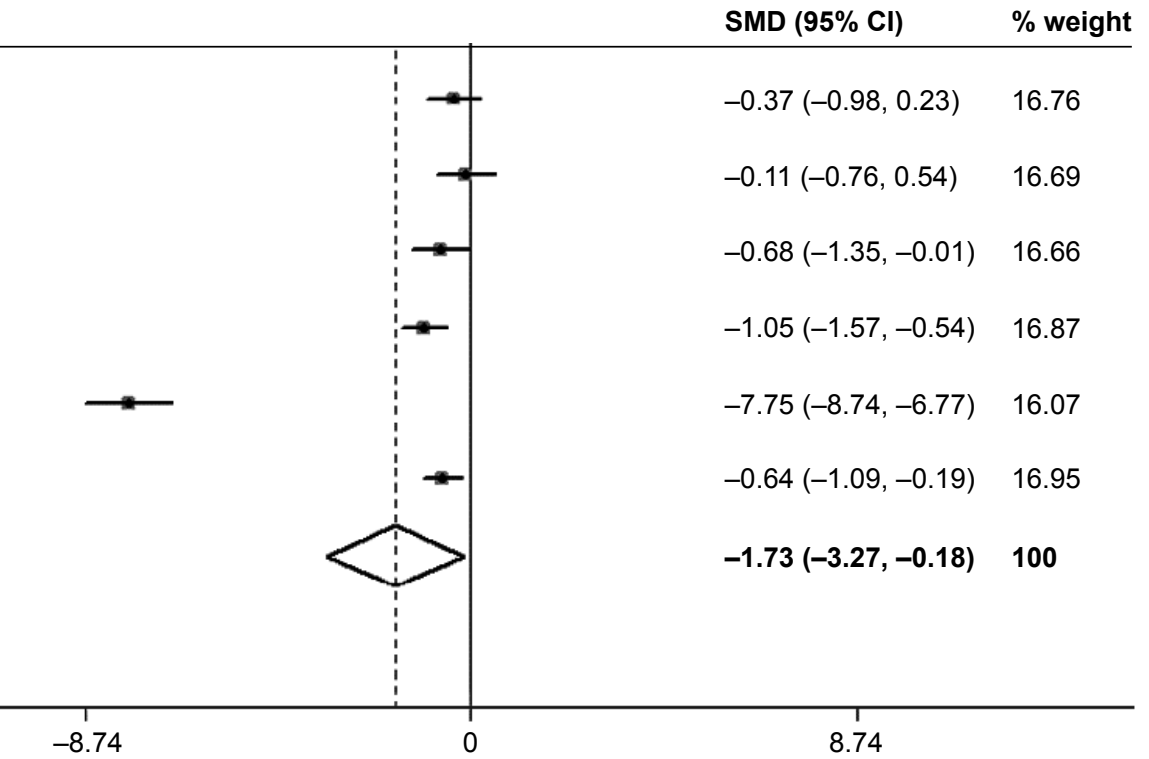

Figure 6 Forest plots for (A) PTH and (B) Vitamin D.

Notes: For each study, the estimate of mean BMD difference and its $95 \% \mathrm{Cl}$ are plotted with a diamond and a horizontal line, respectively. Weights are from random-effects analysis. Terrovitis et a ${ }^{23}$ data shown in order of total group, NYHA I or NYHA II group, and NYHA III or IV group, respectively.

Abbreviations: $\mathrm{BMD}$, bone mineral density; $\mathrm{Cl}$, confidence interval; PTH, parathyroid hormone; SMD, standard mean deviation.

However, bone loss in patients with CHF may also be due to the lower level of serum receptor activator for the nuclear factor- $\kappa$ B ligand (RANKL) and the higher level of osteoprotegerin (OPG) in these individuals. RANKL is a potential stimulator for bone resorption, and OPG subsequently inhibits the RANKL-induced bone loss. ${ }^{6}$ Moreover, Ying-Hsien Chen et $\mathrm{al}^{21}$ also found that OPG was inversely correlated with the trochanteric BMD in patients with CHF. Several possible reasons may contribute to the higher OPG level in patients with CHF. ${ }^{18}$ First, some factors, such as adiponectin, leptin, and natriuretic peptides, ${ }^{4}$ may disturb the level of OPG in the state of CHF. Second, in postmenopausal osteoporotic woman with CHF, the level of OPG was negatively related to BMD. ${ }^{17}$

\section{Limitations}

The present meta-analysis had a number of limitations. First, limited references consisting of only four studies were longitudinal population-level cohort studies, ${ }^{20,25}$ and two were case-report studies. ${ }^{11,22-24}$ Second, the inclusion and exclusion criteria for both CHF and bone mass were different among the studies. The individuals' age, food consumption, and physical activity could directly affect the bone density. In the present study, the average age of the patients was 
57-69.9 years. Bone loss is slow and age related in males at the age of 40-50 years, but the loss is more rapid after the age of 70 years as well as in postmenopausal females. ${ }^{27}$ Third, the pharmacohistory of the individuals was different in the included studies; some drugs had a direct or indirect effect on the bone density. Fourth, not all of the included studies included BMD of the total hip, femoral neck, arms, and so on.

\section{Acknowledgments}

The study was supported by the Health Bureau of Zhejiang Province (2017KY189 and 2017KY001) and the Chinese Traditional Medicine Science and Technology Projects of Zhejiang Province (2017ZB002).

\section{Disclosure}

The authors report no conflicts of interest in this work.

\section{References}

1. Crosson B, McGregor KM, Nocera JR, Drucker JH, Tran SM, Butler AJ. The relevance of aging-related changes in brain function to rehabilitation in aging-related disease. Front Hum Neurosci. 2015;9:307.

2. Xing W, Gao W, Mao G, et al. Long non-coding RNAs in aging organs and tissues. Clin Exp Pharmacol Physiol. 2017 Suppl 1:30-37.

3. JafariNasabian P, Inglis JE, Reilly W, Kelly OJ, Ilich JZ. Aging human body: changes in bone, muscle and body fat with consequent changes in nutrient intake. $J$ Endocrinol. 2017;234(1):R37-R51.

4. St-Onge MP, Gallagher D. Body composition changes with aging: the cause or the result of alterations in metabolic rate and macronutrient oxidation? Nutrition. 2010;26(2):152-155.

5. Moreira NF, da Veiga GV, Santaliestra-Pasias AM, et al. Clustering of multiple energy balance related behaviors is associated with body fat composition indicators in adolescents: results from the HELENA and ELANA studies. Appetite. 2018;120:505-513.

6. Strait JB, Lakatta EG. Aging-associated cardiovascular changes and their relationship to heart failure. Heart Fail Clin. 2012;8(1):143-164.

7. Forman DE, Santanasto AJ, Boudreau R, et al. Impact of incident heart failure on body composition over time in the health, aging, and body composition study population. Circ Heart Fail. 2017;10(9):e003915.

8. Lloyd-Jones D, Adams RJ, Brown TM, et al; American Heart Association Statistics Committee and Stroke Statistics Subcommittee. Heart disease and stroke statistics - 2010 update: a report from the American Heart Association. Circulation. 2010;121(7):e46-e215.

9. Ponikowski P, Voors AA, Anker SD, et al. 2016 ESC guidelines for the diagnosis and treatment of acute and chronic heart failure. Rev Esp Cardiol. 2016;69:1167.

10. Sandri M, Viehmann M, Adams V, et al. Chronic heart failure and aging - effects of exercise training on endothelial function and mechanisms of endothelial regeneration: results from the leipzig exercise intervention in chronic heart failure and aging (LEICA) study. Eur $J$ Prev Cardiol. 2016;23(4):349-358.
11. Jankowska EA, Jakubaszko J, Cwynar A, et al. Bone mineral status and bone loss over time in men with chronic systolic heart failure and their clinical and hormonal determinants. Eur J Heart Fail. 2009; 11(1):28-38.

12. Berliner D, Bauersachs J. Current drug therapy in chronic heart failure: the new guidelines of the European Society of Cardiology (ESC). Korean Circ J. 2017;47(5):543-554.

13. Coats AJ. Heart failure: what causes the symptoms of heart failure? Heart. 2001;86(5):574-578.

14. Lans C, Cider A, Nylander E, Brudin L. Peripheral muscle training with resistance exercise bands in patients with chronic heart failure. Long-term effects on walking distance and quality of life; a pilot study. ESC Heart Fail. Epub November 23, 2017.

15. Krynytska I, Marushchak M, Zaets T, Savchenko I, Habor H. Investigation of bone mineralization in patients with coronary heart disease complicated by chronic heart failure, stage II-A. Georgian Med News. 2017;267:43-48.

16. Lorenc R, Gluszko P, Franek E, et al. Guidelines for the diagnosis and management of osteoporosis in Poland: update 2017. Endokrynol Pol. 2017;68(5):604-609.

17. Notarnicola A, Maccagnano G, Moretti L, Tafuri S, Moretti B. Cardiopathy and osteoporosis: the epidemiology in a region of Italy. $J$ Biol Regul Homeost Agents. 2017;31(1):251-255.

18. Fohtung RB, Brown DL, Koh WJ, et al. Bone mineral density and risk of heart failure in older adults: the cardiovascular health study. $J \mathrm{Am}$ Heart Assoc. 2017;6:e04344.

19. Anker SD, Clark AL, Teixeira MM, Hellewell PG, Coats AJ. Loss of bone mineral in patients with cachexia due to chronic heart failure. Am J Cardiol. 1999;83(4):612-615.

20. Bozic B, Loncar G, Prodanovic N, et al. Relationship between high circulating adiponectin with bone mineral density and bone metabolism in elderly males with chronic heart failure. J Card Fail. 2010; 16(4):301-307.

21. Chen Y-H, Wu Y-W, Yang W-S, et al. Relationship between bone mineral density and serum osteoprotegerin in patients with chronic heart failure. PLoS One. 2012;7(8):e44242.

22. Qian C, Xu S. Observation of osteoporosis in elderly patients with congestive heart failure. Chin J Rural Med Pharm. 2014;21:10-11.

23. Terrovitis J, Zotos P, Kaldara E, et al. Bone mass loss in chronic heart failure is associated with secondary hyperparathyroidism and has prognostic significance. Eur J Heart Fail. 2012;14(3):326-332.

24. Zhu T, Cui L, Zhu N, Wang J, Geng Z, Li Z. Analysis of bone mineral density in patients with chronic heart failure. J Clin Cardiol. 2016; 32:811-814.

25. Abou-Raya S, Abou-Raya A. Osteoporosis and congestive heart failure (CHF) in the elderly patient: double disease burden. Arch Gerontol Geriatr. 2009;49(2):250-254.

26. Nakavachara P, Pooliam J, Weerakulwattana L, et al. A normal reference of bone mineral density (BMD) measured by dual energy X-ray absorptiometry in healthy Thai children and adolescents aged 5-18 years: a new reference for Southeast Asian Populations. PLoS One. 2014;9(5):e97218.

27. Yoshimura H, Matsuda Y, Yamamoto M, Kamiya S, Ishiwata T. Expression and role of long non-coding RNA H19 in carcinogenesis. Front Biosci (Landmark Ed). 2018;23:614-625. 


\section{Supplementary material}

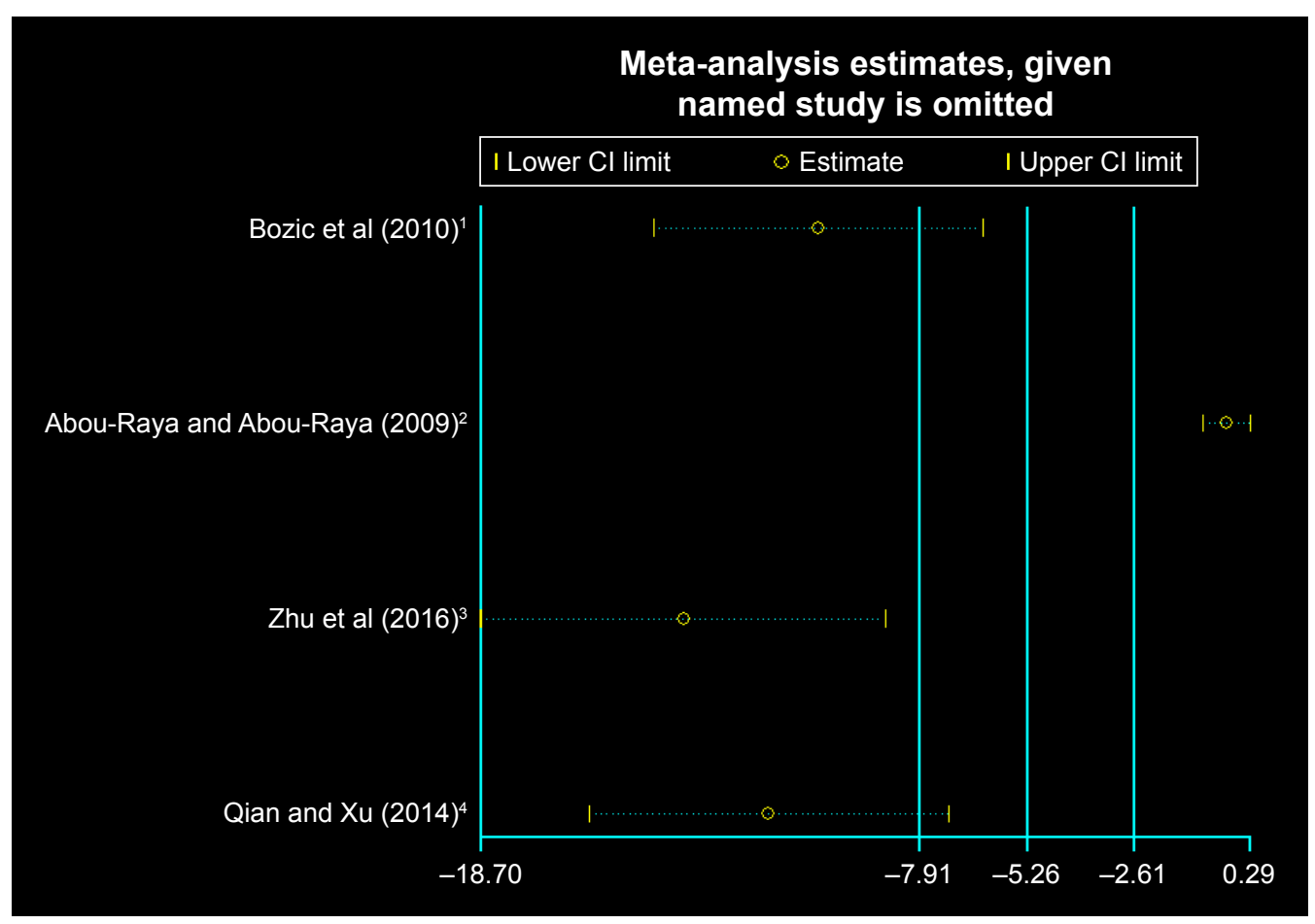

Figure SI The sensitivity analysis of all included studies in lumbar spine.

Note: The combined result varied dramatically after excluding the study reported by Abou-Raya and Abou-Raya. ${ }^{2}$

\section{References}

1. Bozic B, Loncar G, Prodanovic N, et al. Relationship between high circulating adiponectin with bone mineral density and bone metabolism in elderly males with chronic heart failure. J Card Fail. 2010;16(4): 301-307.

2. Abou-Raya S, Abou-Raya A. Osteoporosis and congestive heart failure (CHF) in the elderly patient: double disease burden. Arch Gerontol Geriatr. 2009;49(2):250-254.
3. Zhu T, Cui L, Zhu N, Wang J, Geng Z, Li Z. Analysis of bone mineral density in patients with chronic heart failure. J Clin Cardiol. 2016;32: 811-814.

4. Qian C, Xu S. Observation of osteoporosis in elderly patients with congestive heart failure. Chin J Rural Med Pharm. 2014;21:10-11.
Clinical Interventions in Aging

\section{Publish your work in this journal}

Clinical Interventions in Aging is an international, peer-reviewed journal focusing on evidence-based reports on the value or lack thereof of treatments intended to prevent or delay the onset of maladaptive correlates of aging in human beings. This journal is indexed on PubMed Central, MedLine,
CAS, Scopus and the Elsevier Bibliographic databases. The manuscript management system is completely online and includes a very quick and fair peer-review system, which is all easy to use. Visit http://www.dovepress. com/testimonials.php to read real quotes from published authors. 